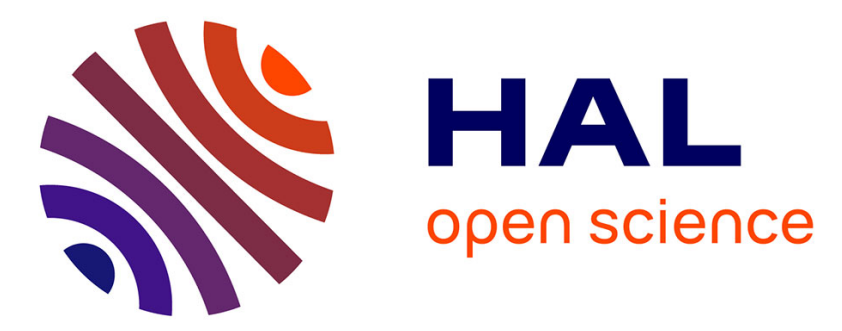

\title{
Predictors of treatment response in rheumatoid arthritis
} Thierry Lequerre, Pascal Rottenberg, Céline Derambure, Pascal Cosette, Olivier Vittecoq

\section{To cite this version:}

Thierry Lequerre, Pascal Rottenberg, Céline Derambure, Pascal Cosette, Olivier Vittecoq. Predictors of treatment response in rheumatoid arthritis. Joint Bone Spine, 2019, 86 (2), pp.151-158. 10.1016/j.jbspin.2018.03.018 . hal-02343605

\section{HAL Id: hal-02343605}

https://hal-normandie-univ.archives-ouvertes.fr/hal-02343605

Submitted on 22 Oct 2021

HAL is a multi-disciplinary open access archive for the deposit and dissemination of scientific research documents, whether they are published or not. The documents may come from teaching and research institutions in France or abroad, or from public or private research centers.
L'archive ouverte pluridisciplinaire HAL, est destinée au dépôt et à la diffusion de documents scientifiques de niveau recherche, publiés ou non, émanant des établissements d'enseignement et de recherche français ou étrangers, des laboratoires publics ou privés.

\section{다)(1) $(5$}

Distributed under a Creative Commons Attribution - NonCommerciall 4.0 International 


\section{Predictors of Treatment Response in Rheumatoid Arthritis}

Thierry Lequerré, ${ }^{\mathrm{a}, \mathrm{b}, *}$, Pascal Rottenberg ${ }^{\mathrm{a}, \mathrm{b}}$, Céline Derambure ${ }^{\mathrm{c}}$, Pascal Cosette ${ }^{\mathrm{d}, \mathrm{e}}$, Olivier Vittecoq $^{\mathrm{a}, \mathrm{b}}$

${ }^{a}$ Inserm U 1234, Normandie Univ, UNIROUEN, 76031 Rouen, France

${ }^{\mathrm{b}}$ Service de Rhumatologie, CHU de Rouen, 76031 Rouen, France

${ }^{\mathrm{c}}$ Normandie Univ, UNIROUEN, Inserm U 1245, 76031 Rouen, France

${ }^{\mathrm{d}}$ UMR-6270, Normandie Université, UNIROUEN, 76031 Rouen, France

${ }^{\mathrm{e}}$ CNRS, Proteomic Facility PISSARO, IRIB, 76821 Mont-Saint-Aignan, France

\section{*Corresponding author:}

Thierry Lequerré

Service de Rhumatologie, Hôpital Charles Nicolle, CHU de Rouen, 1 rue de Germont, 76031 Rouen Cedex, FRANCE

Tel.: +33232889019

Fax: +33232889110

E-mail: thierry.lequerre@ @ chu-rouen.fr 


\section{ABSTRACT}

The expanding array of drugs available for treating rheumatoid arthritis is creating challenges in drug selection for the individual patient. The identification of biomarkers that predict the treatment response prior to drug exposure is therefore a current priority. This new approach, known as theranostics, is a component of personalized medicine, which involves selecting the management strategies that are most effective for a given patient at a given point in time. Antibodies to citrullinated peptides, rheumatoid factor, and the interferon signature are the most robust and best validated biomarkers identified to date. Matrices containing clinical or laboratory parameters of diagnostic or prognostic relevance may help to select the best treatment for the individual patient. Furthermore, the development of largescale approaches requiring no a priori knowledge, such as functional genomics and metabolomics, hold considerable promise, despite persistent difficulties in replicating findings. The complexity of the treatment response in a given patient and substantial variability across patients suggest that biomarkers may be more helpful in combination than singly. The objectives of this review article are to discuss the approaches used to identify theranostic biomarkers and to present an overview of currently available biomarkers and of their performance in everyday clinical practice. However, the range of biomarkers suitable for use in daily practice remains extremely narrow.

Keywords: Rheumatoid arthritis. Biomarkers. Response prediction. Theranostics. Transcriptome. Proteome. 


\section{INTRODUCTION}

The burgeoning assortment of drugs available for treating rheumatoid arthritis (RA) is creating challenges in selecting the best drug for a given patient at a given time. When treatment with a synthetic disease-modifying antirheumatic drug fails, 11 biologic options, without counting biosimilars, are available. These 11 drugs belong to 6 different drug classes with different pathophysiological targets: tumor necrosis factor (TNF) $\alpha$ antagonists, the interleukin (IL)-1 $\beta$ antagonist anakinra, antibodies to the IL-6 receptor (tocilizumab and sarilumab), the anti-CD20 antibody rituximab, the cytotoxic T-lymphocyte-associated protein 4 (CTLA-4)-Ig abatacept, and the janus kinase inhibitors such as baricitinib and tofacitinib. All these biologics produce the same clinical remission rate of only $10 \%$ to $30 \%$, and their efficacy varies over time in individual patients. A personalized approach based on the identification of clinical and/or laboratory predictors of the treatment response in individual patients should therefore prove useful.

Treatment response prediction means that each patient can be informed of the likelihood of a response before being exposed to the drug and that drugs with little potential for efficacy can be avoided, thereby saving time, minimizing costs, and improving the risk/benefit ratio. The rationale for treatment response prediction lies in the pathophysiological, clinical, and therapeutic heterogeneity of RA. Many studies have demonstrated that patients who present with identical clinical manifestations differ markedly regarding their synovial membrane infiltrates and profile of cytokine and gene expression [13]. RA may therefore be better viewed as a syndrome than a disease, with variable contributions of autoimmune and/or inflammatory mechanisms across patients and over time. These differences in patients and time points should therefore be identifiable via differences in biomarkers. The first step to identifying treatment response predictors consists 
in determining what qualifies as a treatment response. Then, the most robust treatment response predictors, or theranostic biomarkers, must be identified. Finally, the approaches used to identify theranostic biomarkers, and those emerging for the future, deserve to be discussed.

\section{DEFINING A TREATMENT RESPONSE}

To identify treatment response predictors, candidates must be assessed in both responders and nonresponders. Therefore, the response to treatment becomes an endpoint that must be defined. Options include the EULAR criteria, criteria for remission, CDAI criteria, ACR criteria, and the structural response. Although the structural response remains the ultimate treatment goal, it is particularly challenging to consider given the variations in structural disease progression across patients having the same degree of disease activity. The pace of structural disease progression varies in an apparently random manner from one patient to the next. In addition, treatment failure may occur as a primary event ( 0 to 6 months) or as an escape phenomenon whose time to occurrence can vary widely with all the available drugs. The best time for assessing the treatment response is also in doubt $(3,6$, or 12 months, or more). Furthermore, in clinical practice the effect of treatment is not binary. In a study of 406 patients given etanercept or infliximab to treat RA, the distributions of outcome parameter values were normal or somewhat skewed but never bimodal, suggesting that the biological mechanisms underpinning the treatment response are multifactorial [4]. Thus, the response is dependent on numerous and complex factors, and biomarkers are therefore more likely to be useful in combination than singly. Finally, the differences across studies in the definition of a treatment response complicates the interpretation of the data. 


\section{Biomarkers identified using a priori approaches}

\subsection{Standard clinical and laboratory biomarkers}

A reasonable assumption was that the clinical and laboratory markers used to establish the diagnosis or prognosis of RA might also help to predict the treatment response. However, numerous studies in patients given TNF $\alpha$ antagonists showed that the only markers in this group of potential usefulness as treatment response predictors were the Health Assessment Questionnaire (HAQ) score, IgA rheumatoid factors (RFs), and anticitrullinated peptide antibodies (ACPAs) [5]. Although RFs and/or ACPAs are extremely potent diagnostic tools and are closely associated with a good response to rituximab or abatacept, a metaanalysis showed that they failed to predict the response to TNF $\alpha$ antagonists [5, 6-8]. Convincing data in the literature are too scant to confirm either RFs or ACPAs as robust treatment response predictors. However, as shown by the SCORE charts for predicting cardiovascular risk, matrices that simultaneously include multiple parameters and can be applied to the individual patient hold considerable promise [9]. In 3280 patients given golimumab for RA, a combination of six baseline parameters (male gender, younger age, lower HAQ score, C-reactive protein [CRP] level or erythrocyte sedimentation rate [ESR], tender or swollen joint count, and absence of comorbidities) was effective in predicting remission or low disease activity [9].

\subsection{Pathophysiological biomarkers}

\subsubsection{Genetic biomarkers}

Many studies have sought to identify gene polymorphisms associated with the response to TNF $\alpha$ antagonists. A metaanalysis of 12 studies including 1721 patients with RA found no evidence that the $G-308 A \mathrm{TNF} \alpha$ polymorphism predicted the response to 
TNF $\alpha$ antagonists [10]. Another study, in 1283 patients from nine cohorts, looked at 31 single nucleotide polymorphisms (SNPs) associated with the risk of RA [11]. By multivariate analysis, the only predictor of meeting EULAR criteria for a response to TNF $\alpha$ antagonist therapy was the $P T P R C$ polymorphism. This predictor was more powerful in patients with than without ACPAs [11]. The predictive performance of the PTPRC polymorphism was confirmed in three large studies including 3153 patients but not in a metaanalysis or in a separate study [12]. In 909 patients taking TNF $\alpha$ antagonists, 187 SNPs spanning 24 genes involved in the toll-like receptor and NFKB signaling systems were genotyped [13]. Among them, eight were associated with a good response to TNF $\alpha$ antagonists, including six for etanercept (MyD88 [rs7744], CHUK [rs11591741 and rs2230804], IKBKB [rs10958713], and TLR-2 [rs5743704 and rs11935252]) and three for infliximab (NFKBIA [rs2233407], TLR-2 [rs11935252], and TLR-4 [rs7045953]) [13]. However, none of these markers was significantly associated with the treatment response after application of Bonferroni's correction for multiple comparisons. A very recent metaanalysis of data on all polymorphisms identified as potentially relevant by several groups found that SNPs failed to improve prediction of the response to TNF $\alpha$ antagonists when added to standard markers [14]. In addition, the candidate SNPs often had limited discriminating ability for each $\mathrm{TNF} \alpha$ antagonist, since the genetic studies were done in patients taking several different TNF $\alpha$ antagonists.

\subsubsection{Protein biomarkers}

Assays of the TNF $\alpha$ protein or messenger RNA in joint fluid, serum, or peripheralblood mononuclear cells (PBMCs) of patients with RA failed to distinguish between future responders and nonresponders to TNF $\alpha$ antagonists. TNF $\alpha$ bioactivity measured as the ability of plasma to induce IL-6 release by synovial cells separated responders from 
nonresponders to infliximab in a study of 198 patients with RA [15]. However, although of interest to research, this bioactivity assay is not available in clinical laboratories and, most importantly, fails to predict the response to each of the various TNF $\alpha$ antagonists. In 72 patients with RA, before the introduction of infliximab therapy, we measured the levels of a host of factors implicated in the pathophysiology of RA including RF and its isotypes, ACPAs, anti- $\alpha$ enolase, anti-calpastatin, anti-keratin, anti-perinuclear factor, anti-glucose- 6 phosphate dehydrogenase, metalloproteases (MMP) -1 and -2 and their inhibitors tissue inhibitors of metalloproteinase (TIMP) -1 and -2, vitamins A and E, selenium, pyridinoline and deoxypyridinoline, soluble receptor activator for nuclear factor $\kappa \mathrm{B}$ ligand (sRANKL), osteoprotegerin (OPG), and cartilage oligomeric matrix protein (COMP) [16]. None of these factors predicted the response to infliximab [16]. In other studies, however, some of these factors (MMP3, COMP, RANKL, or RANKL/OPG ratio) were associated with a good response to infliximab or adalimumab [17-18]. A study of three cohorts of patients with RA used both a protein array of about 545 joint autoantigens and a multiplex assay for 12 cytokines (TNF $\alpha$, IL-1 $\beta$, IL-1 $\alpha$, IL-6, IL-12p40, IL-12p70, IL-15, GM-CSF, FGF-2, MCP1, eotaxin, and IFN $\gamma$-inducible protein 10) [19]. The 24 biomarkers identified in serum samples from 29 patients taking etanercept were then validated in 93 patients. Their positive predictive value (PPV) ranged from $58 \%$ to $72 \%$ and their negative predictive value from $63 \%$ to $78 \%$ [19]. However, these data have not been replicated.

The Multiple Biomarker Disease Activity (MBDA) tool marketed under the brand name VECTRA ${ }^{\circledR}$ is based on serum assays of 12 proteins of interest in RA (IL-6, TNF receptor-1 [TNFR1], vascular cell adhesion molecule-1 [VCAM1], epidermal growth factor [EGF], vascular endothelial growth factor A [VEGF-A], YKL-40, MMP1, MMP3, CRP, serum amyloid A [SAA], leptin, and resistin). A single study has evaluated the performance of this tool for predicting whether infliximab or the methotrexate-sulfasalazine- 
hydroxychloroquine combination would be more effective in patients having failed methotrexate therapy given during the SWEFOT trial [20]. The 1-year rate of a DAS28 response $(<3.2)$ was higher with triple-drug therapy in the patients with an MDBA score $\leq 38$ and was higher with infliximab in those with an MBDA score $>38$ [20]. This interesting finding was not replicated in another study, and the MBDA tool is not yet available in Europe.

\subsubsection{Flow cytometry biomarkers}

Lymphocyte subset profiles may help to predict the treatment response. Responders to methotrexate had normal circulating monocyte counts, and absolute counts of $\mathrm{CD} 14^{\text {+high }} \mathrm{CD} 16^{-}$or $\mathrm{CD} 14^{\text {thigh }} \mathrm{CD} 16^{+}$cells predicted the response to methotrexate after 3 and 6 months with over $70 \%$ sensitivity and over $88 \%$ specificity [21]. In another study, a low count of $\mathrm{CD} 27^{+}$memory B cells emerged as a potential predictor of the response to rituximab [22]. Thus, the identification of lymphocyte or monocyte subset profiles may help to predict the treatment response. Nevertheless, this approach requires complex cytometric analyses and therefore remains better suited to research than to everyday clinical practice.

\section{BIOMARKERS IDENTIFIED USING APPROACHES THAT REQUIRE NO A PRIORI KNOWLEDGE}

Large-scale pharmacogenetic and pharmacogenomic approaches currently offer the greatest promise for identifying treatment response biomarkers. The growth of bioinformatics combined with the miniaturization of tools have made it possible to study the full spectrum of genome polymorphisms, mRNAs, mRNA transcripts (transcriptome), proteins (proteome), or metabolites (metabolome) of a body fluid or tissue at a given point in time (Figure 1). These methods have already proved useful in oncology and have been 
converted to tests for everyday clinical practice [23]. They simultaneously investigate a vast number of parameters in the absence of a priori knowledge about their relevance, with the goal of selecting the candidates most likely to separate responders from nonresponders to a given treatment. As shown in Figure 2, several steps are needed to identify a combination of markers that predicts the treatment response. These large-scale approaches are extremely sensitive for identifying biomarkers not only for each drug class, but also for each drug within a given class. Our experience confirms results showing no overlap whatsoever among biomarkers predicting a response to infliximab, adalimumab, etanercept, tocilizumab, and abatacept [24].

\subsection{Pharmacogenetics}

Although SNP genotyping studies have identified many candidates, replication studies have had a high failure rate [14]. In 89 patients taking TNF $\alpha$ antagonists to treat RA, 317000 SNPs representing about $87 \%$ of all polymorphisms in Europeans were genotyped [25]. Among them, 16, including three for the PON1 gene, were associated with a EULAR treatment response at the level of the individual patient [25]. However, another study failed to replicate these findings in 151 different patients [26]. Data from the Dutch Rheumatoid Arthritis Monitoring (DREAM) registry were used to assess associations between the response to TNF $\alpha$ antagonists and 2557253 SNPs in 882 patients with RA [27]. Although 772 markers were associated with the TNF $\alpha$ antagonist response in the DREAM registry, only three SNPs (rs1568885, rs1813443, rs4411591) were validated in four independent cohorts including 1821 patients in all [27]. This study shows that, despite large sample sizes, results for genetic biomarker combinations often resist replication.

\subsection{Pharmacogenomics: transcriptomes}


The transcriptome is the collection of mRNAs or mRNA transcripts present in a cell or tissue at a given point in time. The abundance of each transcript can be determined and compared across individuals [28]. In a pilot study, we obtained the first evidence that a combination of eight transcripts predicted the response to the methotrexate-infliximab combination with $90 \%$ sensitivity, $70 \%$ specificity, $75 \%$ PPV, and $87.5 \%$ NPV [29]. Most of these transcripts had no known links to TNF $\alpha$ antagonists or RA, underlining the value of a priori approaches. An independent group then replicated our findings by showing that the transcript combination had $71 \%$ sensitivity and $61 \%$ specificity for a treatment response [30]. The interferon signature is the gene combination most often reported to predict the response to immunotherapy [31-35]. In the SMART study, 143 genes were differentially expressed in responders versus nonresponders to rituximab [31]. This gene signature correctly classified $93 \%$ of responders and $100 \%$ of nonresponders. It comprised overexpressed genes centered on the NF- $\kappa \mathrm{B}$ signaling pathway, including IL-33 and the transcription factor STAT5A, and underexpressed genes of the interferon signaling pathway (IFIH1, IFITM1, ISG20, PHF11, SP100, and TRIM22) in the future rituximab responders [31]. IL-33 was then validated in an independent cohort of 185 rituximab-treated patients of whom 138 did and 47 did not respond. The odds ratio (OR) for a treatment response was 2.40 (95\% confidence interval [95\%CI], 1.01-5.72; $p=0.047)$ [32]. Combining IL-33, RF or ACPA, and IgG predicted the response with an OR of 29.61 (95\%CI, 1.30-674.79; $P=0.034)$ relative to patients with none of the three criteria [32]. Other studies further support the use of the whole-blood transcriptome for predicting the treatment response [36, 37]. However, in an analysis of data from the public Gene Expression Omnibus (GEO) obtained from five independent transcriptome studies, the response to TNF $\alpha$ antagonists was predicted by a single gene, GOS2, encoding a protein involved in cell proliferation, apoptosis, inflammation, metabolism, and carcinogenesis [38]. Another study looked at the gene 
combinations identified in eight transcriptome studies done to identify genetic features predicting the response to infliximab in 374 patients with RA, of whom 191 (51.1\%) failed to respond [39]. The response was associated with only five genes (FKBP1A, FGF12, $A N O 1, L R R C 31$, and $A K R 1 D 1)$, which were found in only half (4/8) the combinations. These two metaanalyses illustrate the difficulties encountered in validating and replicating biomarker studies. These difficulties may be ascribable to differences in study methods, evaluation criteria, and bioinformatics approaches. However, the highly encouraging preliminary results demonstrate that transcriptome analysis can identify treatment response predictors. Studies in larger patient populations are needed to minimize the false-positive rate.

\subsection{Pharmacogenomics: proteomes}

The proteome is composed of all the proteins found within a cell or tissue at a point in time. Proteomics involves the investigation of multiple parameters using mass spectrometry techniques (e.g., SELDI-TOF, MALDI-TOF, and iTRAQ). Surface-enhanced laser desorption and ionization (SELDI) applied to plasma samples from 60 patients with RA identified cinq proteins, including apolipoprotein A-1 and platelet factor 4, which had more than $97 \%$ sensitivity and specificity for predicting the response after 30 weeks of infliximab therapy [40]. A label-free quantitation method applied to mass spectra identified 12 proteins (CO7, PROS, TRFE, C1R, CERU, CPN2, IC1, ITIH1, ITIH3, S100A9, ZA2D, and PLMN) in 22 patients taking methotrexate and etanercept, of which two were then validated in 16 different patients as having $88.9 \%$ sensitivity and $100 \%$ specificity for predicting the treatment response $[\mathbf{4 1 , 4 2 ]}$. Proteins in serum samples from 50 etanercept-treated patients with RA were separated by 2D gel electrophoresis then analyzed by mass spectrometry [43]. Four proteins were differentially expressed in responders and nonresponders: 
haptoglobin - $\alpha 1$ and $-\alpha 2$ and the vitamin D-binding protein were overexpressed in responders, whereas apolipoprotein C-III was overexpressed in nonresponders [43]. These studies establish proteomics as an effective method for identifying theranostic markers that can be easily assayed in everyday practice using simpler techniques such as ELISA.

\subsection{Pharmacogenomics: metabolomes}

The pattern of metabolites present in urine, serum, or tissues can be established using spectroscopy coupled with magnetic nuclear resonance or liquid-phase chromatography methods that take advantage of the magnetic properties of certain atomic nuclei [44-46]. A study in 7 responders and 9 nonresponders to 12 months of TNF $\alpha$ antagonist therapy investigated correlations linking urinary metabolites (histamine, glutamine, xanthurenic acid, and ethanolamine) to changes in the DAS28 [45]. In the BIOCURA cohort of 105 patients taking TNF $\alpha$ antagonists, combining four metabolites with several clinical parameters correctly classified $60 \%$ of patients by responder status [46]. All these studies were done in small numbers of patients.

\section{THE MOST ROBUST BIOMARKERS}

\subsection{TNF $\alpha$ antagonists (Table 1)}

Serum calprotectin (MRP8/14 protein complex) is associated with a good response to adalimumab and infliximab, as well as to rituximab $[47,48]$. Combining calprotectin with other markers (baseline DAS28, HAQ score, and RF) correctly identified whether a TNF $\alpha$ antagonist or rituximab was best in $59 \%$ of situations and correctly predicted the response in 63\% of cases [48]. Other serum biomarkers (CXCL13 and ICAM1) predicting the response to adalimumab were identified using synovial-tissue gene expression data then validated on 
serum samples from a different patient cohort [49]. With adalimumab, the ACR50 response rate was $42 \%$ in ICAM ${ }^{\text {high }} /$ CXCL13 ${ }^{\text {low }}$ patients compared to $69 \%$ in ICAM $1^{\text {low }} /$ CXCL1 $3{ }^{\text {high }}$ patients [49]. The interferon signature is the only gene signature that has been proven useful for predicting the response to TNF $\alpha$ antagonists. Plasma interferon bioactivity (with an interferon $\beta / \alpha$ ratio $>0.8$ ) combined with upregulated expression of interferon-related genes in neutrophils was associated with a good response to TNF $\alpha$ antagonists $[\mathbf{5 0 , 5 1 ] .}$

\subsection{Rituximab (Table 2)}

Rituximab is the only drug for which treatment response biomarkers are available. These biomarkers are strongly related to B cells and include RFs, ACPAs, B-cell activating factor, the chemokine CCL19, and $\operatorname{IgG}[\mathbf{6}, \mathbf{5 2}, \mathbf{5 3}]$. Sound evidence exists that RFs, ACPAs, and IgG are associated with a good response to rituximab [22, 52]. In SMART study patients, downregulation of interferon pathway genes (AXL, DHX58, IFIH1, IFITM1, ISG20, MICB, PHF11, SP100, and TRIM22) in future responders correctly classified $92.6 \%$ of patients [31]. These findings were confirmed at the synovial tissue level: upregulation of genes associated with macrophages and T cells and downregulation of genes encoding interferon or remodeling pathway proteins were associated with a better response to rituximab [34]. A few SNPs, some of which were related to interferon (IRF5 rs2004640, SPP1 rs9138 and TNFSF13B rs9514828), were associated with the 24-week response to rituximab [35]. Thus, interferon-related biomarkers hold considerable potential for predicting the response to rituximab, even in patients taking corticosteroid therapy $[\mathbf{3 3}, \mathbf{5 4}]$. An association linking downregulation of genes related to the interferon pathway and a good rituximab response was demonstrated in three studies [33-34]. Overexpression of three interferon-related genes (IFI6, $M X 2$, and $O A S L$ ) was associated with a good response to tocilizumab [37]. 
Low peripheral-blood counts of CD27+ memory B cells were associated with a good response to rituximab after 24 weeks [22]. Peripheral-blood lymphocyte count $>2910 / \mu \mathrm{L}$ or plasmablast count $>2.85 \%$ was $93.3 \%$ sensitive and $44.8 \%$ specific in predicting failure to respond to rituximab within 6 months [55-57]. The usefulness of plasmablast counts for predicting failure to respond was confirmed in the patients of the DANCER, SERENE, and SCRIPT trials, in which an RNA signature expressed by plasmablasts (IgJ and FCRL5) identified nonresponders [58].

\subsection{Abatacept}

A study of pooled data from nine European registries (including the French registry ORA) with over 2700 patients in all established that the presence of RF and/or ACPA was associated with a lower likelihood of premature abatacept discontinuation due to lack of efficacy [7]. In addition, the likelihood of achieving a remission within 6 months was higher in patients with fewer than $28 / \mu \mathrm{L} \mathrm{CD} 4^{+} \mathrm{CD} 28^{-} \mathrm{T}$ cells and fewer than $<87 / \mu \mathrm{L} \mathrm{CD} 8^{+} \mathrm{CD} 28^{-} \mathrm{T}$ cells [59]. Although these data were not replicated in an independent patient population, we showed in 68 patients from the APRAISE study that a response to the methotrexateabatacept combination was predicted by a signature enriched in genes that were significantly downregulated in responders versus nonresponders and that encoded electron transport chain pathway proteins (NDUFA6, NDUFA4, UQCRQ, ATP5J, COX7A2, COX7B, and COX6A1) [36]. Of the 87 transcripts in this signature, four (BLOC1S1, RNASE3, COX6A1, and PTRH2) correctly classified patients with $75 \%$ sensitivity, $85 \%$ specificity, $75 \%$ PPV, and $85 \%$ NPV [42].

\subsection{IL-6 receptor antagonists (Table 3)}


Studies of serum IL-6 levels as a potential predictor of the tocilizumab response have produced diverging results [60-61]. For instance, among patients with serum gp130 levels above $0.2 \mu \mathrm{g} / \mathrm{mL}$, about $60 \%$ were in remission versus only $19 \%$ of patients not in remission, indicating fairly good discriminating power of gp130 [60]. Eight loci, none of which was related to RA or IL-6, were associated with the tocilizumab response. Two of these eight loci, which were SNPs related to CD69 and GALNT18) were validated in another study $[39,62]$. Expression in the synovial membrane of ICAM $1{ }^{\text {high }} /$ CXCL1 $3^{\text {low }}$ was associated with failure to respond to tocilizumab, whereas ICAM $1^{\text {low }} /$ CXCL13 ${ }^{\text {high }}$ was associated with a tocilizumab response [49]. Finally, other biomarkers identified using transcriptomic approaches appear promising, such as genes related to interferon type 1 (IFI6, $M X 2$, and $O A S L$ ); the gene encoding metallothionein 1G; the gene for the TRAV8-3 protein involved in the CD8+ T-cell response; and the genes for the proteins EPHA4, CCDC32, and DHFR [37, 63]. No theranostic biomarkers for sarilumab have been reported to date.

\subsection{JAK inhibitors}

No biomarkers have been identified in published studies.

\section{CONCLUSION}

The number of theranostic biomarkers is very limited. Overall, diagnostic, prognostic, and pathophysiological biomarkers have insufficient discriminating power, the only exceptions being RFs and ACPAs for rituximab and abatacept. However, matrices built using these parameters constitute an innovative avenue of research for predicting the treatment response in individual patients. The transcriptome and proteome approaches requiring no a priori knowledge may be most likely to identify reliable biomarkers (Table 
4). Nevertheless, attempts to replicate the results of studies identifying biomarkers usually failed, due to methodological differences and insufficient sample sizes. Integrative biology is a fast-expanding field that can be expected to identify combinations of parameters capable of predicting the response to various drugs. Personalized medicine thus constitutes a challenge for the near future given the growing number of available drugs. 


\section{Disclosure of interest}

T.L. has received grants or fees for consultancy activities and other interventions from AbbVie, Bristol Myers Squibb, Chugai, Janssen, Lilly, Merck \& Co, Novartis, Pfizer, Roche, Sanofi, SOBI, and UCB.

P.R., C.D., and P.C have no conflicts of interest to disclose.

O.V. has received grants or fees for consultancy activities and other interventions from AbbVie, Bristol Myers Squibb, Chugai, Lilly, Merck \& Co, Pfizer, Roche, and UCB. 


\section{References}

1 Thurlings RM, Wijbrandts CA, Mebius RE, et al. Synovial lymphoid neogenesis does not define a specific clinical rheumatoid arthritis phenotype. Arthritis Rheum 2008;58:1582-9. 2 van Baarsen LG, Wijbrandts CA, Timmer TC, van der Pouw Kraan TC, Tak PP, Verweij CL. Synovial tissue heterogeneity in rheumatoid arthritis in relation to disease activity and biomarkers in peripheral blood. Arthritis Rheum 2010;62:1602-7.

3 Kasperkovitz PV, Timmer TC, Smeets TJ, et al. Fibroblast-like synoviocytes derived from patients with rheumatoid arthritis show the imprint of synovial tissue heterogeneity: evidence of a link between an increased myofibroblast-like phenotype and highinflammation synovitis. Arthritis Rheum 2005;52:430-41.

4. van Vollenhoven RF, Klareskog L. Clinical responses to tumor necrosis factor alpha antagonists do not show a bimodal distribution: data from the Stockholm tumor necrosis factor alpha followup registry. Arthritis Rheum 2003;48:1500-3.

5 Cuppen BV, Welsing PM, Sprengers JJ, et al. Personalized biological treatment for rheumatoid arthritis: a systematic review with a focus on clinical applicability. Rheumatology 2016;55:826-39.

6 Sellam J, Hendel-Chavez H, Rouanet S et al. B cell activation biomarkers as predictive factors for the response to rituximab in rheumatoid arthritis: a six-month, national, multicenter, open-label study. Arthritis Rheum 2011;63:933-8.

7 Gottenberg JE, Courvoisier DS, Hernandez MV, et al. Brief Report: Association of rheumatoid factor and anti-citrullinated protein antibody positivity with better effectiveness of abatacept: results from the Pan-European Registry analysis. Arthritis Rheumatol 2016;68:1346-52. 
$8 \mathrm{Lv}$ Q, Yin Y, Li X, et al. The status of rheumatoid factor and anti-cyclic citrullinated peptide antibody are not associated with the effect of anti-TNF- $\alpha$ agent treatment in patients with rheumatoid arthritis: a meta-analysis. PLoS One 2014;9:e89442.

9 Vastesaeger N, Kutzbach AG, Amital H, et al. Prediction of remission and low disease activity in disease-modifying anti-rheumatic drug-refractory patients with rheumatoid arthritis treated with golimumab. Rheumatology 2016;55:1466-76.

10 Pavy S, Toonen EJ, Miceli-Richard C, et al. Tumour necrosis factor alpha -308G->A polymorphism is not associated with response to TNFalpha blockers in Caucasian patients with rheumatoid arthritis: systematic review and meta-analysis. Ann Rheum Dis 2010;69:1022-8.

11 Cui J, Saevarsdottir S, Thomson B, et al. Rheumatoid arthritis risk allele PTPRC is also associated with response to anti-tumor necrosis factor alpha therapy. Arthritis Rheum 2010;62:1849-61.

12 Romão VC, Vital EM, Fonseca JE, Buch MH. Right drug, right patient, right time: aspiration or future promise for biologics in rheumatoid arthritis? Arthritis Res Ther 2017;19:239.

13 Potter C, Cordell HJ, Barton A, et al. Association between anti-tumour necrosis factor treatment response and genetic variants within the TLR and NF\{kappa\}B signalling pathways. Ann Rheum Dis 2010;69:1315-20.

14 Sieberts SK, Zhu F, García-García J, et al. Crowdsourced assessment of common genetic contribution to predicting anti-TNF treatment response in rheumatoid arthritis. Nat Commun 2016;7:12460.

15 Marotte H, Arnaud B, Diasparra J, Zrioual S, Miossec P. Association between the level of circulating bioactive tumor necrosis factor alpha and the tumor necrosis factor alpha gene 
polymorphism at -308 in patients with rheumatoid arthritis treated with a tumor necrosis factor alpha inhibitor. Arthritis Rheum 2008;58:1258-63.

16 Lequerré T, Jouen F, Brazier M, et al. Autoantibodies, metalloproteinases and bone markers in rheumatoid arthritis patients are unable to predict their responses to infliximab. Rheumatology 2007;46:446-53.

17 González-Alvaro I, Ortiz AM, Tomero EG, et al. Baseline serum RANKL levels may serve to predict remission in rheumatoid arthritis patients treated with TNF antagonists. Ann Rheum Dis 2007;66:1675-8.

18 Visvanathan S, Rahman MU, Keystone E, et al. Association of serum markers with improvement in clinical response measures after treatment with golimumab in patients with active rheumatoid arthritis despite receiving methotrexate: results from the GO-FORWARD study. Arthritis Res Ther 2010;12:R211.

19 Hueber W, Tomooka BH, Batliwalla F, et al. Blood autoantibody and cytokine profiles predict response to anti-tumor necrosis factor therapy in rheumatoid arthritis. Arthritis Res Ther 2009;11:R76.

20 Hambardzumyan K, Saevarsdottir S, Forslind K et al. A multi-biomarker disease activity score and the choice of second-line therapy in early rheumatoid arthritis after methotrexate failure. Arthritis Rheumatol 2017;69:953-963.

21 Chara L, Sánchez-Atrio A, Pérez A, et al. The number of circulating monocytes as biomarkers of the clinical response to methotrexate in untreated patients with rheumatoid arthritis. J Transl Med 2015;13:2.

22 Sellam J, Rouanet S, Hendel-Chavez H, et al. Blood memory B cells are disturbed and predict the response to rituximab in patients with rheumatoid arthritis. Arthritis Rheum 2011;63:3692-701. 
23 Holleman A, Cheok MH, den Boer ML, et al. Gene-expression patterns in drug-resistant acute lymphoblastic leukemia cells and response to treatment. N Engl J Med 2004;351:53342.

24 Ortea I, Roschitzki B, López-Rodríguez R, et al. Independent candidate serum protein biomarkers of response to adalimumab and to infliximab in rheumatoid arthritis: An exploratory study. PLoS One 2016;11:e0153140.

25 Liu C, Batliwalla F, Li W, et al. Genome-wide association scan identifies candidate polymorphisms associated with differential response to anti-TNF treatment in rheumatoid arthritis. Mol Med 2008;14:575-81.

26 Suarez-Gestal M, Perez-Pampin E, Calaza M, Gomez-Reino JJ, Gonzalez A. Lack of replication of genetic predictors for the rheumatoid arthritis response to anti-TNF treatments: a prospective case-only study. Arthritis Res Ther 2010;12:R72-7.

27 Umiċevic Mirkov M, Cui J, Vermeulen SH, et al. Genome-wide association analysis of anti-TNF drug response in patients with rheumatoid arthritis. Ann Rheum Dis 2013;72:137581.

28 Lequerré T, Coulouarn C, Derambure C, et al. A new tool for rheumatology: large-scale analysis of gene expression. Joint Bone Spine 2003;70:248-56.

29 Lequerré T, Gauthier-Jauneau AC, Bansard C, et al. Gene profiling in white blood cells predicts infliximab responsiveness in rheumatoid arthritis. Arthritis Res Ther 2006;8:R105. 30 Toonen EJ, Gilissen C, Franke B, et al. Validation study of existing gene expression signatures for anti-TNF treatment in patients with rheumatoid arthritis. PLoS One 2012;7:e33199.

31 Sellam J, Marion-Thore S, Dumont F, et al. Use of whole-blood transcriptomic profiling to highlight several pathophysiologic pathways associated with response to rituximab in 
patients with rheumatoid arthritis: data from a randomized, controlled, open-label trial. Arthritis Rheumatol 2014;66:2015-25.

32 Sellam J, Rivière E, Courties A, et al. Serum IL-33, a new marker predicting response to rituximab in rheumatoid arthritis. Arthritis Res Ther 2016;18:294.

33 Thurlings RM, Boumans M, Tekstra J, et al. Relationship between the type I interferon signature and the response to rituximab in rheumatoid arthritis patients. Arthritis Rheum 2010;62:3607-14.

34 Hogan VE, Holweg CT, Choy DF, et al. Pretreatment synovial transcriptional profile is associated with early and late clinical response in rheumatoid arthritis patients treated with rituximab. Ann Rheum Dis 2012;71:1888-94.

35 Juge PA, Gazal S, Constantin A, et al. Variants of genes implicated in type 1 interferon pathway and B-cell activation modulate the EULAR response to rituximab at 24 weeks in rheumatoid arthritis. RMD Open 2017;3:e000448.

36 Derambure C, Dzangue-Tchoupou G, Berard C, et al. Pre-silencing of genes involved in the electron transport chain (ETC) pathway is associated with responsiveness to abatacept in rheumatoid arthritis. Arthritis Res Ther 2017;19:109.

37 Sanayama Y, Ikeda K, Saito Y, et al. Prediction of therapeutic responses to tocilizumab in patients with rheumatoid arthritis: biomarkers identified by analysis of gene expression in peripheral blood mononuclear cells using genome-wide DNA microarray. Arthritis Rheumatol 2014;66:1421-31.

$38 \mathrm{Kim}$ TH, Choi SJ, Lee YH, Song GG, Ji JD. Gene expression profile predicting the response to anti-TNF treatment in patients with rheumatoid arthritis; analysis of GEO datasets. Joint Bone Spine 2014;81:325-30.

39 Huang QL, Zhou FJ, Wu CB, Xu C, Qian WY, Fan DP, Cai XS. Circulating Biomarkers for Predicting Infliximab Response in Rheumatoid Arthritis: A Systematic Bioinformatics Analysis. Med Sci Monit. 2017;23:1849-55. 
40 Trocmé C, Marotte H, Baillet A, et al. Apolipoprotein A-I and platelet factor 4 are biomarkers for infliximab response in rheumatoid arthritis. Ann Rheum Dis 2009;68:132833.

41 Obry A, Lequerré T, Hardouin J, et al. Identification of S100A9 as biomarker of responsiveness to the methotrexate/etanercept combination in rheumatoid arthritis using a proteomic approach. PLoS One 2014;9:e115800.

42 Obry A, Hardouin J, Lequerré T, et al. Identification of 7 proteins in sera of RA patients with potential to predict ETA/MTX treatment response. Theranostics 2015;5:1214-24.

43 Blaschke S, Rinke K, Maring M, et al. Haptoglobin- $\alpha 1$, - $\alpha 2$, vitamin D-binding protein and apolipoprotein C-III as predictors of etanercept drug response in rheumatoid arthritis. Arthritis Res Ther 2015;17:45.

44 Tatar Z, Migne C, Petera M, et al. Variations in the metabolome in response to disease activity of rheumatoid arthritis. BMC Musculoskelet Disord 2016;17:353.

45 Kapoor SR, Filer A, Fitzpatrick MA, et al. Metabolic profiling predicts response to antitumor necrosis factor $\alpha$ therapy in patients with rheumatoid arthritis. Arthritis Rheum 2013; $5: 1448-56$

46 Cuppen BV, Fu J, van Wietmarschen HA, et al. Exploring the Inflammatory Metabolomic Profile to Predict Response to TNF- $\alpha$ Inhibitors in Rheumatoid Arthritis. PLoS One 2016;11:e0163087.

47 Abildtrup M, Kingsley GH, Scott DL. Calprotectin as a biomarker for rheumatoid arthritis: a systematic review. J Rheumatol 2015;42:760-70.

48 Nair SC, Welsing PM, Choi IY, et al. A Personalized Approach to Biological Therapy Using Prediction of Clinical Response Based on MRP8/14 Serum Complex Levels in Rheumatoid Arthritis Patients. PLoS One 2016;11:e0152362. 
49 Dennis G Jr, Holweg CT, Kummerfeld SK, et al. Synovial phenotypes in rheumatoid arthritis correlate with response to biologic therapeutics. Arthritis Res Ther 2014;16:R90. 50 Wright HL, Thomas HB, Moots RJ, Edwards SW. Interferon gene expression signature in rheumatoid arthritis neutrophils correlates with a good response to TNFi therapy. Rheumatology 2015;54:188-93.

51 Mavragani CP, La DT, Stohl W, Crow MK. Association of the response to tumor necrosis factor antagonists with plasma type I interferon activity and interferon-beta/alpha ratios in rheumatoid arthritis patients: a post hoc analysis of a predominantly Hispanic cohort. Arthritis Rheum 2010;62:392-401.

52 Chatzidionysiou K, Lie E, Nasonov E, et al. Highest clinical effectiveness of rituximab in autoantibody-positive patients with rheumatoid arthritis and in those for whom no more than one previous TNF antagonist has failed: pooled data from 10 European registries. Ann Rheum Dis 2011;70:1575-80.

53 Sellam J, Rouanet S, Hendel-Chavez H, et al. CCL19, a B cell chemokine, is related to the decrease of blood memory B cells and predicts the clinical response to rituximab in patients with rheumatoid arthritis. Arthritis Rheum 2013;65:2253-61.

54 de Jong TD, Sellam J, Agca R, et al. A multi-parameter response prediction model for rituximab in rheumatoid arthritis. Joint Bone Spine 2018;85:219-26.

55 Stradner MH, Dejaco C, Brickmann K, Graninger WB, Brezinschek HP. A combination of cellular biomarkers predicts failure to respond to rituximab in rheumatoid arthritis: a 24week observational study. Arthritis Res Ther 2016;18:190.

56 Vital EM, Dass S, Rawstron AC, et al. Management of nonresponse to rituximab in rheumatoid arthritis: predictors and outcome of re-treatment. Arthritis Rheum 2010;62:12739. 
57 Brezinschek HP, Rainer F, Brickmann K, Graninger WB. B lymphocyte-typing for prediction of clinical response to rituximab. Arthritis Res Ther 2012;14:R161.

58 Owczarczyk K, Lal P, Abbas AR, et al. A plasmablast biomarker for nonresponse to antibody therapy to CD20 in rheumatoid arthritis. Sci Transl Med 2011;3:101ra92.

59 Scarsi M, Ziglioli T, Airo P. Baseline numbers of circulating CD28-negative T cells may predict clinical response to abatacept in patients with rheumatoid arthritis. J Rheumatol 2011;38:2105-11.

60 Uno K, Yoshizaki K, Iwahashi M, et al. Pretreatment prediction of individual rheumatoid arthritis patients' response to anti-cytokine therapy using serum cytokine/chemokine/soluble receptor biomarkers. PLoS One 2015;10:1-15.

61 Wang J, Platt A, Upmanyu R, et al. IL-6 pathway-driven investigation of response to IL-6 receptor inhibition in rheumatoid arthritis. BMJ Open 2013;3:e003199.

62 Maldonado-Montoro M, Cañadas-Garre M, González-Utrilla A, Plaza-Plaza JC, CallejaHernández MÁ. Genetic and clinical biomarkers of tocilizumab response in patients with rheumatoid arthritis. Pharmacol Res 2016;111:264-27.

63 Mesko B, Poliska S, Szamosi S, et al. Peripheral blood gene expression and IgG glycosylation profiles as markers of tocilizumab treatment in rheumatoid arthritis. $\mathbf{J}$ Rheumatol 2012;39:916-28. 
Table 1: Candidate markers for predicting the response to TNF $\alpha$ antagonists

\section{Clinical and laboratory markers}

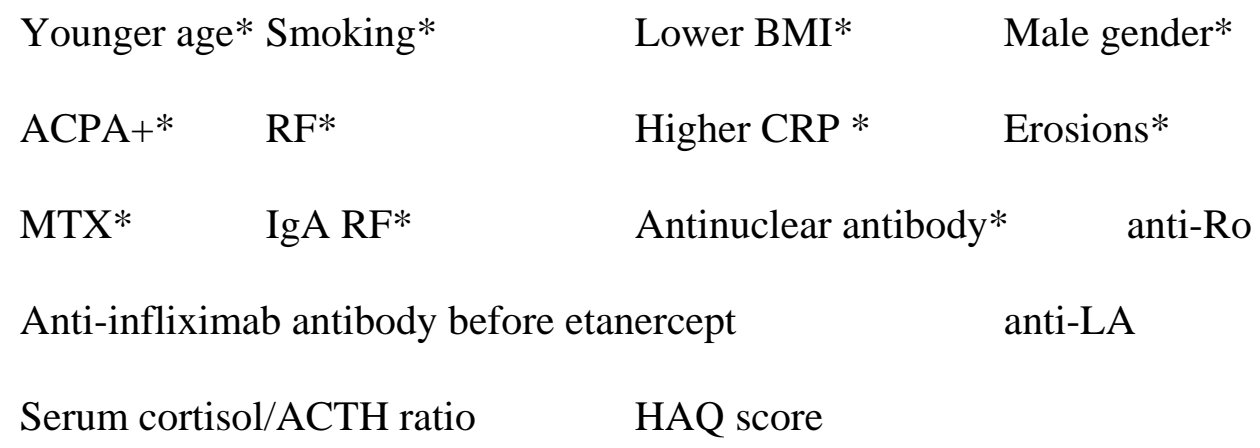

\section{Genetic markers (SNPs)}

Fc gamma receptor $3 \mathrm{~A}(158 \mathrm{~V}>\mathrm{F}$, FF genotype)*

Fc gamma receptor $2 \mathrm{~A}(131 \mathrm{H}>\mathrm{R}, \mathrm{RR}$ genotype)

IL-6 promoter (174G >C, GG genotype)*

TNF promoter (308 G > A, GG genotype)*

sIL-6R A/C (AA+AC genotype)

TNF- $\alpha$ promoter $(857 \mathrm{C} / \mathrm{T}, \mathrm{CT}+\mathrm{TT}$ genotype $)$

TNF- $\alpha$ promoter (238 G/A, GG genotype)

IL1 $\beta$ (-3954 C/T, CC genotype)

IL1-RN (-2018 T/C, TT genotype)

Shared epitope, carrier

HLA-DRB1

MAKK14 (rs916344) C/G

MAP2K6 (rs11656130) T/G

RPS6KA4 (rs475032) G/C

RPS6KA5 (rs1286112) C/G

MAP2K6 (rs2716191) T/C 
RPS6KA5 (rs1286076) C/T

MAPKAPK2 (rs4240847) C/A

TRAILR1 G/C (genotype CC genotype)

TNFR1A A/G (AA genotype)

LTA $+720 \mathrm{C} / \mathrm{A}$ (CC genotype)

IL-10-1087 A/G (AA genotype)

TNFRII-codon 196 T/G (TT genotype)

PTGS2 G/A (GG genotype)

NFkBIB rs3136645 T/C (TT genotype)

TNFi TLR-2 C/G (CC genotype)

NFkBIB rs9403, G/C (GG genotype)

IRAK-3 T/A (TA genotype)

CHUK (GG genotype)

MyD88 A/G (AG genotype)

TLR-10/1/6 A/C (CC genotype)

IKBKB A/C (AC genotype)

MIF 173G/C, C-allele carrier

MIF (CATT)n repeat, CATT-7

TNFRSF1B-196 M/R (MM genotype)

FCGR3A-212V/F (FF genotype)

TNFSF1b 676T/G (GT genotype)

PDE3A-SLCO1C1

CD84

rs10919563 G > A related to the PTPRC gene

PON1 
rs1568885, rs1813443, rs4411591

\section{Transcripts or proteins}

Apolipoprotein A-1

Platelet factor 4

Higher serum MRP8/14 ratio

IgG antibodies to mutated citrullinated vimentin MRP8/14

Anti-CEP antibodies

Anti-FBP antibodies

IL-1 $\beta>4.84 \mathrm{pg} / \mathrm{mL}$

MMP3*

COMP*

RANKL*

RANKL/OPG*

GOS2

FKBP1A, FGF12, ANO1, LRRC31, AKR1D1

CO7, PROS, TRFE, C1R, CERU, CPN2, IC1, ITIH1, ITIH3, S100A9, ZA2D, PLMN

Haptoglobins- $\alpha 1$ and $\alpha 2$,

Vitamin D-binding protein

Apolipoprotein C-III

interferon $\beta / \alpha$ ratio $>0.8$

\section{Cytometric markers}

$\mathrm{ICAM}^{\text {high }} / \mathrm{CXCL} 13^{\text {low }}$

\section{Histological markers}

Lymphocyte aggregates 


\section{Metabolomic markers}

histamine, glutamine, xanthurenic acid, ethanolamine

sn1-LPC(18:3- $\omega 3 / \omega 6)$, sn1-LPC(15:0), ethanolamine, and lysine 
Table 2: Candidate markers for predicting the response to rituximab

\section{Clinical and laboratory markers}

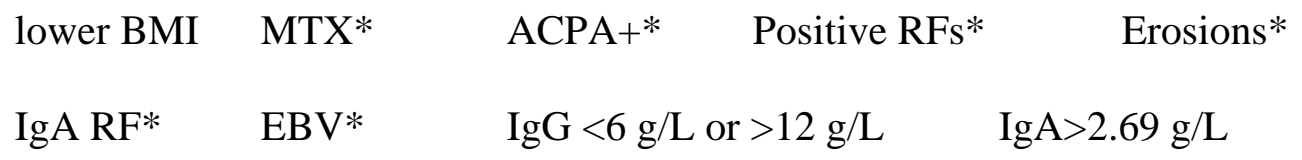

\section{Gene markers}

SNP of the Fc gamma receptor 3A (158 V > F, VV genotypes)*

SNP of BAFF (871 C>T, CC genotype)

SNP related to the IL-6 promoter (174G > C, GC and CC genotypes)

SNP related to the TNF promoter (308 G > A, GA genotype)

SNP TGF $\beta 1(10 \mathrm{~T}>\mathrm{C}, \mathrm{TC}$ genotype $)$

SNP TGF $\beta 1$ (25 G > C, GC genotype)

Anti-CMV antibodies

\section{Transcripts or proteins}

Higher serum MRP8/14 ratio

Downregulated expression of interferon-related genes (whole blood)* miRNA125B (whole blood)

IgG antibodies to mutated citrullinated vimentin MRP8/14

Signaling pathway centered on NF- $\kappa \mathrm{B}$

IL-33

STAT5A

Interferon signaling pathway (IFIH1, IFITM1, ISG20, PHF11, SP100, TRIM22)

Interferon signature (LY6E, HERC5, IFI44L, ISG15, MxA, MxB, EPSTI1 et RSAD2)

\section{Cytometric markers}

Lower count of CD $27^{+}$memory B cells 


\section{Metabolomic markers}

phenylalanine, 2-hydroxyvalerate, succinate, choline, glycine, acetoacetate, tyrosine 
Table 3: Candidate markers for predicting the response to tocilizumab

\section{Clinical and laboratory markers}
Younger age Current smoking
Lower BMI*
Higher CRP* High-titer RFs MTX

\section{Genetic markers}

SNP related to IL-6

SNP related to IL-6R

$\begin{array}{lllll}\text { Rs703505 Rs11052877 } & \text { Rs49100008 Rs9598957 Rs10108210 }\end{array}$

Rs703297 Rs1560011 Rs7055107

Transcripts or proteins

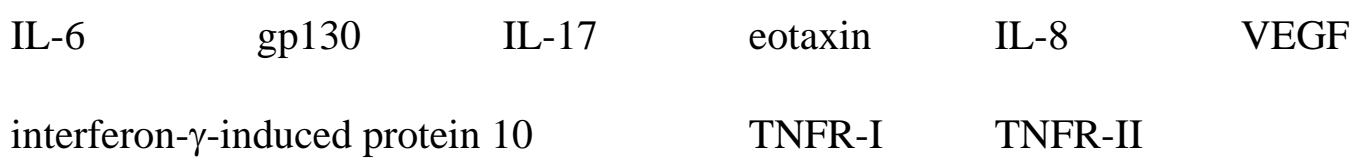

\section{Cytometric markers}

Low count of $\mathrm{CD}^{2} 7^{-} \mathrm{IgD}^{-} \mathrm{B}$ cells

High count of Treg cells

NK CD $3^{-}{ }^{C D} 56^{+}$cells 
Table 4: Most robust biomarkers for predicting the treatment response

\section{To TNF $\alpha$ antagonists}

calprotectin MRP8/14

interferon signature

To rituximab

IL-33

FR, ACPA, and IgG level

To abatacept

RF and/or ACPA 


\section{FIGURE LEGENDS}

Figure 1: Large-scale exploratory methods requiring no a priori knowledge

\section{Figure 2: Identification of biomarkers predicting the treatment response}

The identification of biomarkers capable of predicting the treatment response, or theranostic markers, involves the following steps: (i) large-scale scans in responders and nonresponders to identify the most likely candidates; (ii) validation studies of combinations in a different patient population using simpler tools that are more appropriate for a limited number of biomarkers (e.g., RT-PCR or ELISA); (iii) and evaluation of the clinical relevance of the markers thus identified in different patients and in formal clinical trials. 
Figure $1 \uparrow$

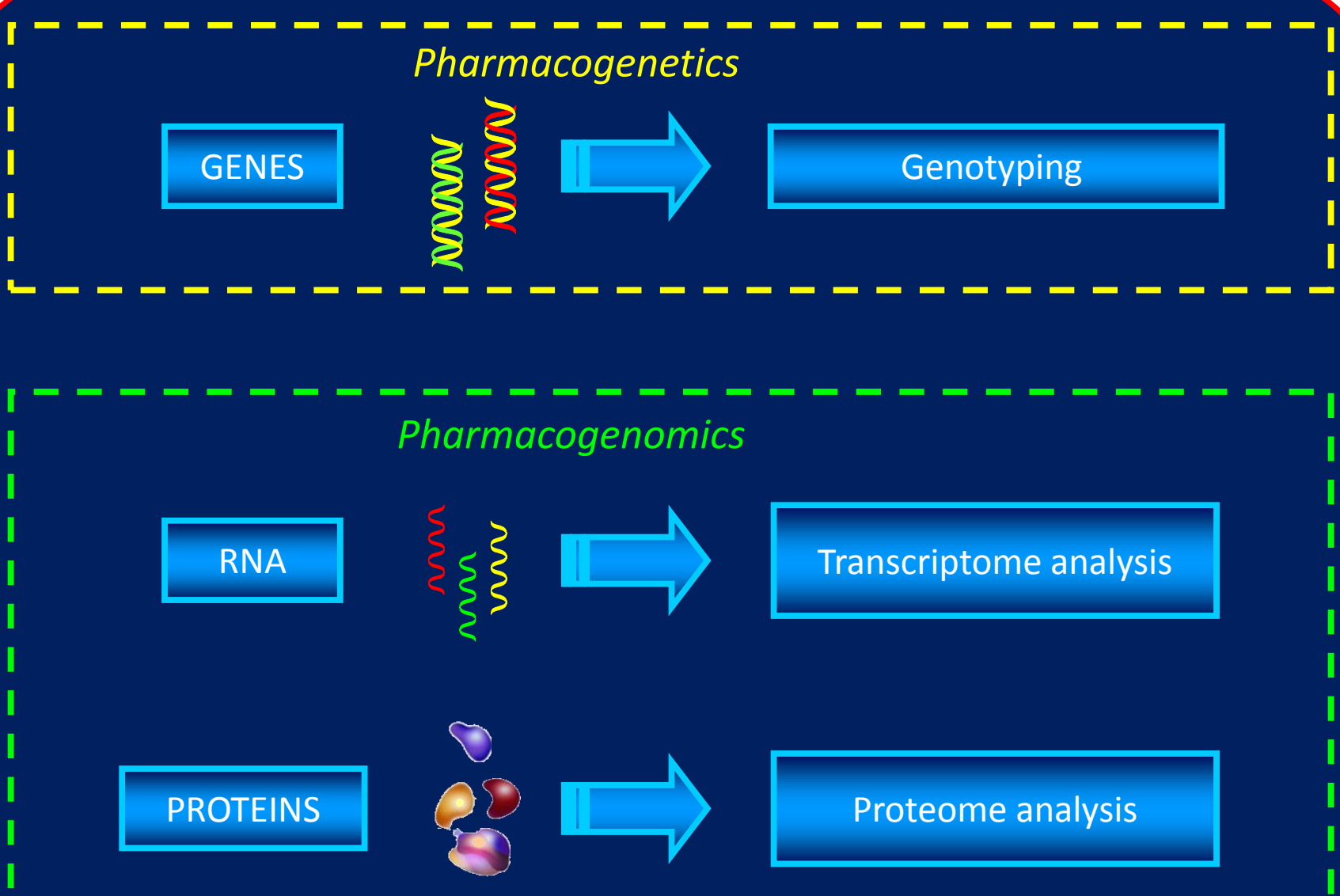

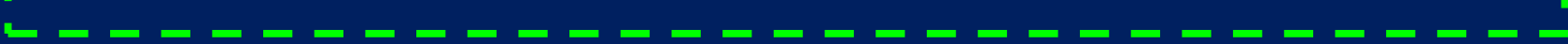

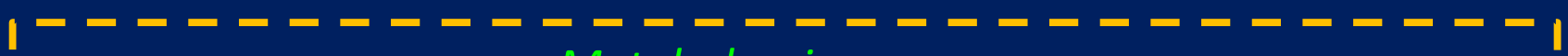
Metabolomics

METABOLITES

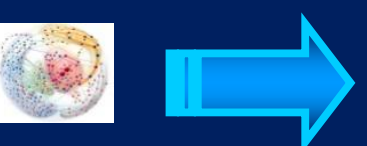

Metabolome analysis 
Figure $2 \uparrow$

\section{TRAINING}

$1^{\text {st }}$ patient population

\section{Combination of biomarkers}
VALIDATION

$2^{\text {nd }}$ patient population

\section{Large-scale validation in different patients}

